NBER WORKING PAPER SERIES

\title{
ELECTORAL MANIPULATION VIA EXPENDITURE COMPOSITION: THEORY AND EVIDENCE
}

\author{
Allan Drazen \\ Marcela Eslava \\ Working Paper 11085 \\ http://www.nber.org/papers/w11085 \\ NATIONAL BUREAU OF ECONOMIC RESEARCH \\ 1050 Massachusetts Avenue \\ Cambridge, MA 02138 \\ January 2005
}

We wish to thank Miguel Rueda for excellent research assistance, and participants at seminars at University of Maryland and Hebrew University of Jerusalem, the Vth meeting of the Political Economy Network of LACEA, and the 9th Annual Meeting of LACEA for many useful comments. The first author wishes to thank National Science Foundation, grant 418412, the Israel Science Foundation, and the Yael Chair of Comparative Economics, Tel Aviv University, for financial support. The views expressed herein are those of the author(s) and do not necessarily reflect the views of the National Bureau of Economic Research.

(C) 2005 by Allan Drazen and Marcela Eslava. All rights reserved. Short sections of text, not to exceed two paragraphs, may be quoted without explicit permission provided that full credit, including $\odot$ notice, is given to the source. 
Electoral Manipulation via Expenditure Composition: Theory and Evidence

Allan Drazen and Marcela Eslava

NBER Working Paper No. 11085

January 2005

JEL No. ID72, E62, D78

\title{
$\underline{\text { ABSTRACT }}$
}

We present a model of the Political Budget Cycle in which voters and politicians have preferences for different types of government spending. Incumbents try to influence voters by changing the composition of government spending, rather than overall spending or revenues. Rational voters may support an incumbent who targets them with spending before the election even though such spending may be due to opportunistic manipulation, because it can also reflect sincere preference of the incumbent for types of spending voters favor. Classifying expenditures into those which are targeted to voters and those that are not, we provide evidence supporting our model in data on local public finances for all Colombian municipalities. Our findings indicate both a pre-electoral increase in targeted expenditures, combined with a contraction of other types of expenditure, and a voter response to targeting.

\author{
Allan Drazen \\ Department of Economics \\ University of Maryland \\ College Park, MA 20742 \\ and NBER \\ drazen@econ.umd.edu \\ Marcela Eslava \\ Universidad de Los Andes \\ Carrera 1 N 18A-70, Bloque C \\ Bogota, Colombia \\ eslava@uniandes.edu.co
}




\section{Introduction}

It is widely believed that incumbent politicians increase public spending before elections to improve the chances that they (or their party) will be re-elected. It is not obvious however why such changes would generate electoral benefits if voters are rational. Rational individuals should vote on the basis of the policies they expect each candidate will undertake after the election, rather than on past outcomes. Furthermore, they should anticipate eventual incentives of the incumbent to manipulate fiscal policy before an election, and therefore not respond to such manipulation.

To reconcile fiscal expansions before elections with voter rationality, Rogoff (1990) and Rogoff and Sibert (1988) suggested that high pre-election expenditures that are visible to voters may serve as a signal of "competence", meaning the ability to provide more public goods. A politician has private information about his own level of competence, which exhibits some persistence over time. Voters face a signal extraction problem: they cannot observe competence directly and therefore use spending on some types of goods before an election to infer post-electoral competence. As a result, an incumbent running for re-election has an incentive to increase spending in those items voters observe. For instance, while in Rogoff (1990) voters observe some types of government expenditure, in Shi and Svensson (2002) they observe the overall level of spending, but not all voters observe the deficit. In this approach, a fiscal expansion before an election can be an effective tool to gain support from imperfectly informed voters.

However, the view that increasing aggregate spending or deficits before an election is an effective tool to gain votes has been questioned. Peltzman (1992) shows that voters in the US are less likely to support a local official who has increased overall spending before the election. Brender (2003) finds evidence that, when voters in Israel are able to effectively monitor the fiscal choices of local officials, incurring in large pre-election deficits actually harms an incumbent's chances of being re-elected. Brender and Drazen (2005) find in a large panel of countries that deficits over the previous three years reduce an incumbent's re-election chances in developed countries and established democracies. Similarly, our findings below indicate that the share of votes received by the incumbent's party is decreasing in the level of the deficit in the year preceding the election. It would therefore appear that well informed voters not only are hard to "buy" through spending increases, they are actually averse to high overall government spending and deficits.

Politicians appear to be aware of this. Brender and Drazen (2004) show that empirical results 
suggesting that election-year increases in spending or deficits are a widespread phenomenon (see Shi and Svensson [2002a, 2002b] and Persson and Tabellini [2003]) are driven by the experience of "new" democracies, that is, by the first few elections in countries that have made the transition to democracy. ${ }^{1}$ Once new democracies are removed from a larger sample, no statistically significant political deficit cycle is found among established democracies. One is left with the question of whether there is room for electoral manipulation of the budget in established democracies, characterized by well informed and sophisticated voters.

We therefore suggest a different approach, where political budget cycles emerge even if voters dislike high government expenditure and budget deficits, and even if they are able (unlike the models in the Rogoff tradition) to perfectly observe fiscal policy. Political manipulation takes the form of changing the composition of government spending, allowing its overall level (and the deficit) to remain unchanged. Voters value some goods more than others, so that an opportunistic politician may be induced to shift the composition of pre-election spending towards these goods. What voters want to infer is then whether a politician's preferences over the composition of the budget are actually close to their own or whether his pre-election spending choices are meant simply to gain votes. This would explain why there is an incentive for incumbents to increase some types of spending, even if voters are "fiscal conservatives" in the sense of being averse to large overall levels of government spending. Electoral manipulation arises even with fully rational voters, given that they must try to infer the incumbent's preferences from his fiscal behavior. Voters thus rationally respond to pre-election increases in their most preferred types of spending. ${ }^{2}$

The strength of the political cycle in our model depends on the distribution of ideological preferences, and on the amount of information voters have about the political environment. As is probably not surprising, targeted spending increases more prior to elections the larger is the fraction of swing voters in the electorate. However, in our model voters anticipate this behavior. As a result, when a large fraction of voters is undecided, high levels of targeted spending are recognized as being politically motivated, rather than being interpreted as an effective signal of the politician's fiscal

\footnotetext{
${ }^{1}$ Akhmedov and Zhuravskaya (2004) find an electoral expenditure cycle in regional elections in Russia after its transition to democracy, which becomes smaller with each new round of regional elections.

${ }^{2}$ Lindbeck and Weibull (1987) and Dixit and Londregan (1996) present formal models of balanced-budget targeting of voter groups, but these models assume that a politician can commit himself to a post-electoral fiscal policy. There is no voter inference problem about post-electoral utility based on pre-electoral economic magnitudes, so the question of why rational, forward-looking voters who are targeted before the election vote for the incumbent is not really answered.
} 
preferences. This creates a natural limit to electorally motivated increases in spending. On the other hand, the incumbent's ability to engage in this form of electoral manipulation is increased by its access to privileged information about the political environment. In particular, politicians in our model may have more information than voters about the potential electoral benefits of increasing targeted expenditures (i.e. how "swing" voters are). This increases their ability to obtain political support from increases in targeted expenditures, as voters cannot determine if the targeting is politically motivated.

In a related paper (Drazen and Eslava [2005]), we develop a model where expenditures can be targeted to different groups with heterogeneous preferences, and politicians have preferences over different interest groups. As a result, before elections the composition of expenditures is tilted towards the goods favored by groups with greater electoral importance. The incumbent's privileged information about the relative electoral impact of targeting one group or another gives him the ability to raise votes from targeting those groups with spending, even though all voters are aware of the electoral incentives he faces.

We present empirical evidence below on these electoral composition effects, using a new data set we compiled on local government spending and local elections for all Colombian municipalities. Obviously, a classification of government expenditure into targeted and non-targeted expenditures is not readily available, or straightforward. In fact, all government expenditures (probably with the exception of interest payments on external debt) generate benefits for at least some groups in society, even if it is only to those individuals who provide the services and goods to the government. However, we argue that some of the components of expenditure that local governments report separately - in Colombia in particular, most categories of investment expenditures - are more likely to reflect what we call targeted expenditures than others. Consistent with our model, we find that most categories of investment of spending show pre-election expansions, while many components of current spending contract. Furthermore, we investigate the effect of pre-election fiscal policy on the share of votes received by the incumbent party. We find evidence that voters reward incumbents who increase investment spending, but only to the extent that they do so without running large election-year deficits.

Our results on electoral composition effects are consistent with some previous findings. Brender (2003) finds that voters in Israel penalize election year deficits, but also that they reward high expen- 
diture in development projects in the year previous to an election. Similarly, Peltzman (1992) result that US voters punish government spending holds for current (as opposed to capital) expenditures, but is weaker if investment in roads, an important component of public investment, is included in his policy variable. ${ }^{3}$ Similarly, Alesina, Perotti, and Tavares (1998) argue that in the OECD there is no evidence of a systematic electoral penalty or fall in popularity for governments that enact policies of significant fiscal restraint. Kneebone and McKenzie (2001) look for evidence of a political budget cycle for Canadian provinces, and find no evidence of a cycle in aggregate spending, but do find a cycle in what they call "visible expenditures", mostly investment expenditures such as construction of roads and structures. Very similar findings are reported for Mexico by Gonzalez (2002), who also finds that other categories of spending, such as current transfers, contract prior to elections. Surprisingly, these regularities, as well as their potential implications for the theory of political budget cycles, seem to have gone overlooked.

The paper is organized as follows. In section 2 we present the model and solve for the politicaleconomic equilibrium with a budget composition cycle. In section 3 we discuss relevant empirical evidence for the case of Colombia. Section 4 contains conclusions.

\section{A Simple Model}

We present a simple two-period model, with an election between an incumbent and a challenger at the end of the first period, where incumbents use the composition of expenditures to attract votes. We make extreme assumptions about the distribution of politician types and the distribution of voter preferences, the two key "primitives" of the problem, in order to derive the main results as simply as possible. The political budget cycle is represented simply as the difference in fiscal choices between the pre-election period and the post-election period. Our results, however, do not depend on the simplicity of the assumptions on the distributions or the existence of only one election cycle. ${ }^{4}$

Voters value certain types of expenditures, but dislike deficits. We simply assume that incumbents can neither change the overall level of spending, taxes, or deficits, reflecting the aversion of voters

\footnotetext{
${ }^{3} \mathrm{He}$ interprets the "odd findings" obtained when including expenditure in roads as a result of the high lumpiness of this component. However, in light of the other evidence reviewed here, we view them as the reflection that voters in fact support the undertaking of development projects.

${ }^{4}$ In Drazen and Eslava (2005) we develop a more elaborate model with multiple elections and less restrictive assumptions about the distributions. The focus is groups with different fiscal preferences, rather than on voters who all have the same preferences. The conceptual results we show below also hold in such type of framework.
} 
to high overall spending and deficits. Targeting voters with one type of spending requires reducing another type, where we focus on such targeting. The choice of fiscal policy is thus the composition of the budget.

The incumbent politician has preferences over the composition of the budget which may differ from those of voters. For simplicity, we assume that all voters have the same preferences over types of expenditure and receive the same amount of goods, so the heterogeneity of interest over the budget is between voters and politicians, rather than across groups of voters, as in Drazen and Eslava (2005). Here, voters differ from one another only in their preferences over policies other than targeted expenditures (termed "ideology").

\section{$2.1 \quad$ Voters}

An voter trades off ideology over non-fiscal policy, $\pi$, and utility from targeted expenditures, $g_{t}$, in deciding whether to support a candidate. The idea of targeted expenditures is close to that in Lindbeck and Weibull (1987) or Dixit and Londregan (1996), but in a setting where expectations of future policy are key to determining how an individual votes. (See footnote 2.)

Utility of an individual depends on two factors, each of which may be influenced by government policy. First, there is the consumption of the government supplied good $g_{t} \geq 0$ which provides utility directly. (We abstract here from private consumption, since taxes are fixed.) Second, an individual $j$ also cares about the distance between his most desired position $\tilde{\pi}^{j}$ over non-fiscal policies (which is immutable) and the positions $\pi^{I}$ of the current incumbent $I$ and $\pi^{C}$ of the challenger. We take these as fixed and, without loss of generality, assume $\pi^{I}<\pi^{C}$. In the post-election period, either the initial incumbent $I$ or the challenger $C$ may be in power, depending on the election outcome.

Single period utility of individual $j$ in period $t$ if politician $P \in\{I, C\}$ is in power may be written:

$$
U_{t}^{j}(P)=V\left(g_{t}^{P}\right)-\left(\tilde{\pi}^{j}-\pi^{P}\right)^{2}
$$

where $V^{\prime}(\cdot)>0, V^{\prime \prime}(\cdot)<0$, and $g_{t}^{P}$ is expenditure chosen by policymaker $P$. A voter $j$ is thus characterized by $\tilde{\pi}^{j}$. (To help in following the exposition, note that $V\left(g_{t}^{P}\right)$ does not depend on $j$. Hence in discussing the problem of inferring $g_{2}$ from $g_{1}$, we may ignore the index $j$.)

An individual's only decision is whether to vote for the incumbent or the challenger, and only in an election period. We therefore focus on utility as of period 1, when the election takes place. The 
present expected discounted utility of individual $j$ as of period 1 is:

$$
W_{1}^{j}=U_{1}^{j}(I)+\beta E_{1} U_{2}^{j}(P)
$$

where $\beta$ is the discount factor, and $P \in\{I, C\}$. In the election, a voter prefers the incumbent over the challenger if he expects to receive more utility from the former in $t=2$.

\subsection{Politicians}

There are two government provided goods: $g_{t}$; and $K_{t}$, a good which the politician values but which voters do not. One may think, for example, of politicians who value managing a large bureaucracy. (For simplicity of exposition we call $K_{t}$ "desks".) However, the idea we have in mind is more general: voters may value some government services less than others for many reasons, such as voters' failure to recognize the positive externalities these services produce, or the low visibility of some types of expenditure. The characterization of $K_{t}$ as total waste in the eyes of voters is simply an extreme way to capture those differences in the value assigned by voters to different goods and services provided by the government. Each period, the government thus faces a budget constraint:

$$
T=K_{t}+g_{t}
$$

where $T$ is a fixed and exogenous level of tax revenue.

The politician's objective is to maximize a weighted sum of voters' utility, a fixed value $\chi$ of being in office, and the value of "desks" $K_{t}$. We denote by $\omega_{P t}$ the weight a politician $P$ puts on voters relative to desks in period $t$. A politician $P^{\prime} s$ objective in the post-election period, $t=2$, can then be written:

$$
\Omega_{2}^{P}=\omega_{P 2}\left[V\left(g_{2}\right)+\sum_{j=1}^{N} \frac{\left(\tilde{\pi}^{j}-\pi^{P}\right)^{2}}{N}\right]+a\left(K_{2}\right)+\chi
$$

where $N$ is the size of the voting population, which we assume to be constant and $a(K)$ is an increasing, concave function. We have written this objective in per-capita terms for simplicity.

The weight $\omega_{P t}$, known to the politician but not observed by voters, is crucial to a voter's choice. The level of $g_{2}$ the politician would choose is, by (4), known to be a function of $\omega_{P 2}$, so that rational voters vote on the basis of their beliefs about $\omega_{I 2}$ and $\omega_{C 2}$. The crucial assumptions in our argument 
that election-year fiscal policy may be used to gain votes are that the weight the politician puts on voters' utility is not observed by the voters (and hence must be inferred), but is correlated over time (so that fiscal policy observed before the election provides information on the politician's preferences and hence spending allocation in the post-election period). Voters must try to infer the value of $\omega_{I 2}$ from observations on $g_{1}$, that is, on expenditures before the election. For clarity of exposition, we assume the process governing the evolution of the $\omega_{P t}$ takes the simplest possible form that satisfies the conditions discussed above. First, $\omega_{P t}$ does not change from $t=1$ to $t=2$, with $\omega_{P 1}=\omega_{P 2} \equiv \omega_{P}$ for $P \in\{I, C\} .{ }^{5}$ Second, for any politician $P, \omega_{P}$ can take on two values: $\omega_{P}=\{\bar{\omega}, \underline{\omega}\}$ with prior probabilities $\operatorname{Pr}(\omega=\bar{\omega})=\bar{p}$ and $\operatorname{Pr}(\omega=\underline{\omega})=(1-\bar{p})$. We suppose $\bar{\omega}>\underline{\omega}$, so that a politician of type $\bar{\omega}$ cares more about targeting expenditures to people (a people politician), while $\omega_{P}=\underline{\omega}$ makes the politician more interested in bureaucracy than targeting (a desks politician).

In the election year, the incumbent chooses $g_{1}$ trying to maximize his lifetime utility. Abstracting from constant terms, we write this objective as:

$$
\Omega_{1}^{I}=\omega_{I} V\left(g_{1}^{I}\right)+a\left(K_{1}\right)+\beta \rho\left(g_{1}^{I}\right) \Omega_{2}^{I}+\beta\left(1-\rho\left(g_{1}^{I}\right)\right) \Omega_{2}^{C}
$$

where $\beta$ is a discount factor and $\rho$ is the probability of re-election which, given that voters use $g_{1}$ to make inferences the incumbent's preferences, is a function of $g_{1}$. We will solve for the function $\rho(\cdot)$ from voter's behavior, assuming voters are forward looking. Note that, since ideological positions of both voters and candidates are given, the argument that relates to ideology is a constant in both periods.

One solves the problem backwards, starting with the post-election period. In $t=2$, a government $P(P=I, C)$ maximizes (4) by choice of $g_{2}^{P}$ subject to the budget constraint (3). The solution is given by the following first-order condition:

$$
\omega_{P} V^{\prime}\left(g_{2}^{P}\right)=a^{\prime}\left(T-g_{2}^{P}\right)
$$

for each $P$, that is, the politician equalizes his marginal utility from the two uses of expenditure.

Concavity of $V(g)$ and $a(K)$ implies that the postelection targeted expenditures to voters are

\footnotetext{
${ }^{5}$ In a multiperiod model, this assumption needs to be modified so that $\omega_{P 1}$ cannot be perfectly inferred from previous policy. An alternative that satisfies this requirement is that $\omega_{P t}$ follows an MA(1) process, analogous to the evolution of competence in Rogoff (1990).
} 
increasing in the weight the politician gives to voter welfare, so that $g_{2}(\bar{\omega})>g_{2}(\underline{\omega})$. We will denote $g_{2}(\underline{\omega})=\underline{g}$, and suppose for simplicity that $\bar{\omega}=\infty$, so that a "people-type" politician always chooses the maximum level of expenditures possible, that is, $g_{2}(\bar{\omega})=T>\underline{g}$. This assumption simplifies the solution but, as we discuss later, we could dispense of it and still prove that politicians are expected to engage in pre-election increases in targeted expenditures.

In the election period, the incumbent chooses $g_{1}$ to maximize his objective (5), subject to the budget constraint (3). A politician may then choose a value of $g_{1}$ different from what he would choose in the non-election period, if by doing so he can significantly increase his chances of being reelected, represented by $\rho$. Given our assumption that $\bar{\omega}=\infty$, a people politician would provide the maximum possible $g_{t}$ even in the non-election period, so he would not change his policy in the election period. A desks policymaker (one characterized by $\underline{\omega}$ ), however, has two choices. He may choose $g_{1}(\underline{\omega})=\underline{g}$, his non-election period optimum, but thus reveal his type. Or, he may choose $g_{1}(\underline{\omega})=T>\underline{g}$ to influence the election outcome by mimicking a people policymaker, whom voters prefer given that $g_{2}$ is increasing in $\omega .{ }^{6}$ He will choose high $g$ if the current utility benefit from choosing his non-electoral preferred policy (low $g$ ) is smaller than the benefit derived from increasing his re-election chances through high targeted expenditures. More formally, the desks-type incumbent will choose high targeted spending in the election period if

$$
\Delta \Omega<\beta(\rho(T)-\rho(\underline{g}))(\Delta \Omega \bar{p}+\chi)
$$

where $\Delta \Omega$ is the current utility gain to a policy maker of $\underline{\omega}$ type of choosing his own policy:

$$
\Delta \Omega \equiv \underline{\omega}[V(\underline{g})-V(T)]+[a(T-\underline{g})-a(0)]>0
$$

Note that the benefit from choosing high $g$ in $t=1$, given by the right-hand side of (7), depends on both the gain in re-election probability, $\rho(T)-\rho(\underline{g})$, and the value of being re-elected. The latter includes not only the exogenous value of being in office, but also the value of having one's preferred policy in $t=2$ rather than the challenger's, which is non-zero only if the challenger is of a different type. This explains the presence of $\bar{p}=\operatorname{Pr}\left(\omega_{P}=\bar{\omega}\right)$ in condition (7).

The following lemma summarizes the incumbent's behavior, where a type $\underline{\omega}$ incumbent may

\footnotetext{
${ }^{6}$ Since any choice of $g_{1}$ other than $T$ will reveal a policymaker to be of type $\underline{\omega}$, in a separating equilibrium he will choose $\underline{g}$.
} 
either pool with a type $\bar{\omega}$ or separate from him:

Lemma 1: (Incumbent's Strategy)

In the election period, the incumbent's optimal choice of targeted expenditures $g_{1}\left(\omega_{I}\right)$ is characterized by the following policy rule:

$$
g_{1}\left(\omega_{I}=\bar{\omega}\right)=T
$$

and

$$
g_{1}\left(\omega_{I}=\underline{\omega}\right)=\left\{\begin{array}{l}
T \text { if } \Delta \Omega<\beta(\rho(T)-\rho(\underline{g}))(\Delta \Omega \bar{p}+\chi) \\
\underline{g} \text { otherwise }
\end{array}\right\}
$$

\subsection{Voting behavior and election outcomes}

We now consider the choice problem of voters. Let $E\left[V\left(g_{2}\right) \mid P, g_{1}\right]$ be the voter's expectation of his utility from government expenditures in $t=2$ if politician $P$ is elected at the end of $t=1$, conditional on observed $g_{1}$. He votes for the incumbent if he expects to receive higher utility in $t=2$ under the incumbent than the challenger. That is, voter $j$ votes for the incumbent if

$$
E\left[V\left(g_{2}\right) \mid I, g_{1}^{I}\right]-\left(\tilde{\pi}^{j}-\pi^{I}\right)^{2}>E\left[V\left(g_{2}\right) \mid C\right]-\left(\tilde{\pi}^{j}-\pi^{C}\right)^{2}
$$

where $\pi^{I}$ and $\pi^{C}$ are known, as is $g_{2}(\omega)$ for $\omega=(\bar{\omega}, \underline{\omega})$. However, $j$ has imperfect information about both $\omega_{I}$ and $\omega_{C}$. To infer the challenger's position, he has no other information than the ex-ante distribution of $\omega$, summarized by the prior $\operatorname{Pr}\left(\omega_{C}=\bar{\omega}\right)=\bar{p}$. On the other hand, voters can use the realization of $g_{1}$ to update their information about the incumbent's type. Using Bayes' rule and the prior $\bar{p}$, voters form a posterior on $\bar{\omega}$, denoted $\bar{p}_{1}$, according to:

$$
\bar{p}_{1}\left(g_{1}^{I}\right) \equiv \operatorname{Pr}\left(\omega=\bar{\omega} \mid g_{1}^{I}\right)=\frac{\operatorname{Pr}\left(g_{1}^{I} \mid \omega=\bar{\omega}\right) \operatorname{Pr}(\omega=\bar{\omega})}{\operatorname{Pr}\left(g_{1}^{I}\right)}
$$

Equation (9) captures the rationality of voting in response to election year fiscal policy. Specifically, since voters know a people type politician never chooses low expenditures $\left(\operatorname{Pr}\left(g_{1}=\underline{g} \mid \omega=\bar{\omega}\right)=0\right)$, upon observing $g_{t}=\underline{g}$ they assign a zero probability to the incumbent having $\omega_{I}=\bar{\omega}$. That is:

$$
\bar{p}_{1}\left(g_{1}^{I}=\underline{g}\right)=0
$$


On the other hand,

$$
\bar{p}_{1}\left(g_{1}^{I}=T\right)=\frac{\bar{p}}{\bar{p}+(1-\bar{p}) q}
$$

where $q=\operatorname{Pr}\left(g_{1}=T \mid \omega=\underline{\omega}\right) \leq 1$ is the probability that a desk-type politician will choose $g_{1}=T$ in the election period. Note the obvious characteristic of Bayesian updating: $\bar{p}_{1}\left(g_{1}^{I}=T\right)>\bar{p}$ iff $q<1$; if $q=1$, then $\bar{p}_{1}(T)=\bar{p}$.

The nature of voters' posterior beliefs reflects an essential characteristic of the political equilibrium. A politician provides high election year expenditures favored by voters in order to convince them that he would also choose high targeted expenditures after the election. However, this signal is only effective to in affecting voters' perceptions if this political incentive is not so large that any politician would provide high electoral expenditures, no matter what his post-election preferences will be. Formally, setting $g_{1}^{I}=T$ has no effect on voting if $q=1$.

We can now rewrite the condition under which voter $j$ prefers the incumbent over the challenger, condition (8), as:

$$
\left(\bar{p}_{1}\left(g_{1}\right)-\bar{p}\right)[V(T)-V(\underline{g})]>\left(\tilde{\pi}^{j}-\pi^{I}\right)^{2}-\left(\tilde{\pi}^{j}-\pi^{C}\right)^{2}
$$

where the left hand side represents the expected gain in utility from consumption if the incumbent is reelected, and the right hand side represents the expected loss in utility from ideological issues if reelection occurs.

To illustrate, we consider the following simple example of voters' ideological preferences. Voters may hold one of three ideological positions: $\tilde{\pi}^{j}=\left\{\hat{\pi}^{I}, \hat{\pi}^{M}=\frac{\pi^{I}+\pi^{C}}{2}, \hat{\pi}^{C}\right\}$. Voters with $\tilde{\pi}^{j}=\hat{\pi}^{I}$ are the incumbent's core voters: they are sufficiently left of center that they vote for the incumbent even if he is known to be of the desks type, that is, even if $\bar{p}_{1}=0$. Analogously, voters with $\tilde{\pi}^{j}=\hat{\pi}^{C}$ are the challenger's core voters: they are sufficiently right of center that they vote for the challenger even if the incumbent is known to be of the people type. ${ }^{7}$ In the middle are voters with $\tilde{\pi}^{j}=\hat{\pi}^{M}$, swing voters in that they are ideologically as close to one candidate as they are to the other. They

${ }^{7}$ Formally, using (11), one may derive

$$
\hat{\pi}^{I}<\frac{\pi^{I}+\pi^{C}}{2}-\bar{p}\left[\frac{V(T)-V(\underline{g})}{2\left(\pi^{C}-\pi^{I}\right)}\right]
$$

and

$$
\hat{\pi}^{C}>\frac{\pi^{I}+\pi^{C}}{2}+(1-\bar{p})\left[\frac{V(T)-V(\underline{g})}{2\left(\pi^{C}-\pi^{I}\right)}\right]
$$


therefore vote on the basis of the fiscal policy they expect to see from the candidates. They vote for the incumbent if and only if they believe he is more likely than the challenger to have high $\omega$, that is, iff $\bar{p}_{1}\left(g_{1}^{I}\right)>\bar{p}$. (If $\bar{p}_{1}\left(g_{1}^{I}\right)=\bar{p}$, swing voters are indifferent between the two candidates, and vote to reelect the incumbent with some probability $r$, which will be analyzed in section 2.4, where we study the equilibrium. ${ }^{8}$ The crucial point is that swing voters may be led to vote for the incumbent by high pre-election targeted expenditure, since they assign some probability to the event that targeting reflects high preference of the incumbent for targeted spending, rather than purely electoral motives.

We summarize the behavior of voters in:

Lemma 2: (Voting Strategies)

In an election between the incumbent and a challenger, the optimal voting strategy of an individual $j$ is given by:

1) If $\tilde{\pi}^{j}=\hat{\pi}^{I}$ individual $j$ votes for the incumbent with probability 1

2) If $\tilde{\pi}^{j}=\hat{\pi}^{C}$ individual $j$ votes for the challenger with probability 1

3) If $\tilde{\pi}^{j}=\hat{\pi}^{M} \equiv \frac{\pi^{C}+\pi^{I}}{2}$ individual $j$ votes for the incumbent with probability $r\left(g_{1}\right)$, where

$$
\begin{array}{ll}
r\left(g_{t}\right)=1 & \text { if } \bar{p}_{1}\left(g_{1}\right)>\bar{p} \\
r\left(g_{t}\right) \in[0,1] & \text { if } \bar{p}_{1}\left(g_{1}\right)=\bar{p} \\
r\left(g_{t}\right)=0 & \text { if } \bar{p}_{1}\left(g_{1}\right)<\bar{p}
\end{array}
$$

where $\bar{p}_{1}\left(g_{1}\right)$ is derived from Bayes' rule, so that $\bar{p}_{1}(\underline{g})=0$, and $\bar{p}_{1}(T)=\frac{\bar{p}}{\bar{p}+(1-\bar{p}) q}$.

Given the voting strategies in lemma 2, election outcomes are easy to characterize. Let $\phi_{I}, \phi_{C}$, and $\phi_{M}$ be the fraction of voters with $\tilde{\pi}^{j}$ equal to $\hat{\pi}^{I}, \hat{\pi}^{C}$, and $\hat{\pi}^{M}$, respectively. The election is decided by simple majority rule. ${ }^{9}$ The incumbent obtains $\phi_{I}$ of the votes if $\bar{p}_{1}<\bar{p}, \phi_{I}+r \phi_{M}$ if $\bar{p}_{1}=\bar{p}$, and $\phi_{I}+\phi_{M}$ of the votes otherwise. In other words, the incumbent is re-elected if $\bar{p}_{1}>\bar{p}$ or if $\bar{p}_{1}=\bar{p}$ and $\phi_{I}+r \phi_{M} \geq \frac{1}{2}$. For the time being, we assume that both voters and politicians have perfect information about $\phi_{I}, \phi_{M}$, and $\phi_{C}$. We further assume that neither group of core voters constitute an absolute majority (that is, $\phi_{I}<\frac{1}{2}$ and $\phi_{C}<\frac{1}{2}$ ), meaning no candidate can win the election without getting the votes of at least some swing voters, and a candidate supported by all

\footnotetext{
${ }^{8}$ These assumptions about ideological preferences are a simple way to capture only some voters being influenced by fiscal policy, while others have such strong positions on other issues that pay no attention to this dimension. By dividing the population in these three groups we simplify things by having each voter worry only about one policy dimension.

${ }^{9}$ We assume, without loss of generality, that a tie is resolved in favor of the incumbent.
} 
swing voters wins the election for sure.

The assumption that no group of core voters is a majority implies that an incumbent who chooses low pre-election targeted spending will not be reelected, since voters recognize him as being of the desks type. Hence, $\rho\left(g_{1}^{I}=\underline{g}\right)=0$. If the incumbent chooses $g_{1}^{I}=T$ and $q=1$ (a deskstype incumbent chooses $g_{1}=T$ with certainty), then swing voters are indifferent between the two candidates $\left(\bar{p}_{1}\left(g_{1}^{I}\right)=\bar{p}\right)$. Then, $\rho(T)=1$ if and only if $\phi_{I}+r\left(g_{1}^{I}\right) \phi_{M} \geq \frac{1}{2}$, that is, if indifferent voters choose the incumbent with high enough probability, and there are enough swing voters. On the other hand, if $g_{1}^{I}=T$ and $q<1$, then $\bar{p}_{1}\left(g_{1}^{I}\right)>\bar{p}$, then swing voters strictly prefer the incumbent and $\rho(T)=1$, since $\phi_{I}+\phi_{M}>\frac{1}{2}$.

\subsection{Political-economic equilibrium}

We can now characterize possible political-economic equilibria. The equilibrium concept is Perfect Bayesian Equilibrium. A pair of strategies (for the incumbent and voters) is an equilibrium if: 1) the voter's strategy is optimal given his beliefs and the incumbent's strategy in choosing $g_{1}$, where beliefs are formed according to Bayes' rule (that is, his strategy satisfies lemma 2); and 2) the incumbent's choice of $g_{1}$ is optimal given voting behavior and the implied election outcomes (that is, it satisfies lemma 1).

Given our assumptions, the strategies of a people-type incumbent $(\omega=\bar{\omega})$ and of both types of core voters $\left(\pi^{j}=\hat{\pi}^{I}, \hat{\pi}^{C}\right)$ are trivial. We therefore discuss only the strategies of a desks-type incumbent $(\omega=\underline{\omega})$ and a swing voter $\left(\pi^{j}=\pi^{M}\right)$. The strategies in lemmas 1 and 2 imply that there are only three possible types of equilibria:

Pooling Equilibrium: A desks-type incumbent chooses $g_{1}=T$ with probability $q=1$, and

swing voters vote for the incumbent with probability $r\left(g_{1}\right)=\left\{\begin{array}{c}\bar{r} \geq \frac{1 / 2-\phi_{I}}{\phi_{M}} \text { if } g_{1}=T \\ 0 \text { otherwise }\end{array}\right\}$. Note that there do not exist pooling equilibria with $r\left(g_{1}=T\right)<\frac{1 / 2-\phi_{I}}{\phi_{M}}$, since then a desks-type incumbent would be better off deviating to $\operatorname{Pr}\left(g_{1}=T\right)=0$.

Separating Equilibrium: A desks-type incumbent chooses $g_{1}=T$ with probability $q=0$ and swing voters vote for the incumbent if and only if $g_{t}=T$.

Mixed Strategy Equilibrium: A desks-type incumbent chooses $g_{1}=T$ with probability $q \in(0,1)$ and swing voters vote for the incumbent if and only if $g_{t}=T$.

These three sets of strategies indeed constitute equilibria, since no player wants to deviate from 
his strategy, given the other's strategy.

Proposition 1 describes the equilibrium outcomes depending on whether a desks politician gives higher value to re-election or to using part of the budget to provide desks rather than expenditure favored by voters (that is, whether $\beta(\bar{p} \Delta \Omega+\chi$ ) is greater than or less than $\Delta \Omega$, the current utility gain to a policy maker of $\underline{\omega}$ type of choosing his own policy). As above, the Proposition focuses on the case where swing voters shift the outcome of the election.

\section{Proposition 1 (Political-Economic Equilibrium)}

When neither type of core voter constitutes an absolute majority, there are three possible politicaleconomic equilibria, depending on parameter values:

Case 1) If $\beta(\bar{p} \Delta \Omega+\chi)>\Delta \Omega$, the optimal strategy for a desks-type incumbent $(\omega=\underline{\omega})$ is $\operatorname{Pr}\left(g_{1}=T\right)=1$. The optimal strategy for swing voters $\left(\pi^{j}=\pi^{M}\right)$ is to vote for the incumbent with probability $r\left(g_{1}\right)=\left\{\begin{array}{c}\bar{r} \geq \frac{0.5-\phi_{I}}{\phi_{M}} \text { if } g_{1}=T \\ 0 \text { otherwise }\end{array}\right\}$

Case 2) If $\beta(\bar{p} \Delta \Omega+\chi)=\Delta \Omega$, the optimal strategy for the desks-type incumbent is $\operatorname{Pr}\left(g_{1}=T\right)=$ $q \in[0,1)$. The optimal strategy for swing voters is $r\left(g_{1}\right)=\left\{\begin{array}{ll}1 & \text { if } g_{1}=T \\ 0 & \text { otherwise }\end{array}\right\}$

Case 3) If $\beta(\bar{p} \Delta \Omega+\chi)<\Delta \Omega$, the optimal strategy for the desks-type incumbent is $\operatorname{Pr}\left(g_{1}=T\right)=0$. The optimal strategy for swing voters is $r\left(g_{1}\right)=\left\{\begin{array}{ll}1 & \text { if } g_{1}=T \\ 0 & \text { otherwise }\end{array}\right\}$.

Proof: Note first that all of these sets of strategies constitute equilibria, since given the voters' strategy the incumbent's satisfies Lemma 1, and given the incumbent's strategy the voters' satisfies Lemma 2. Second, to prove that in each case only the type of equilibrium described exists, note that a separating (pooling) equilibrium cannot be supported if $\beta(\bar{p} \Delta \Omega+\chi)>\Delta \Omega(<\Delta \Omega)$ because the incumbent would deviate to $g_{t}(\underline{\omega})=T\left(g_{t}(\underline{\omega})=\underline{g}\right)$. Moreover, an equilibrium where the incumbent plays mixed strategies can only exist if he is indifferent between the two policies, which happens iff $\beta(\bar{p} \Delta \Omega+\chi)=\Delta \Omega$.

Proposition 1 implies that, provided re-election is valuable enough, a political budget cycle will exist in which: 1) expenditures targeted to voters are expected to be higher in an election than a non-election period (the actual level will depend on which type of politician is in office); and 2) (swing) voters will rationally vote for an incumbent who provides higher targeted expenditures even though they know that such expenditures may be electorally motivated. 
Specifically, the proposition shows that if re-election is valuable enough, a desks-type incumbent will choose $g_{1}=T$ with some positive probability in an election period, while in the post-election period, he chooses $g_{2}=\underline{g}$ with certainty. This implies that the unconditional expectation of government expenditure targeted to voters is higher in the pre-election period, compared to the expected value for other periods. ${ }^{10}$ Conversely, non-targeted expenditures are expected to be lower prior to an election than in other periods. In other words, fiscal policy exhibits cycles with the timing of the election. These cycles take the form of a change in the composition of expenditures, which shift towards targeted expenditures in election periods.

Of course, a political budget cycle of this form will only appear if the incentives to influence the election are large enough. There are two parts to this requirement. The first refers to the preferences of politicians: electoral manipulation of the budget will only arise if $\beta(\bar{p} \Delta \Omega+\chi) \geq \Delta \Omega$, so that the incumbent assigns a large value to being reelected. There is, however, an additional necessary condition, namely that swing voters (those whose votes depend on fiscal policy) can change the outcome of the election $\left(\phi_{I}+\phi_{M} \geq \frac{1}{2}\right)$. The existence of a political budget cycle therefore depends on the political environment, in particular in the potential electoral benefit from convincing swing voters of supporting the incumbent.

What is interesting about the apparently obvious condition on the need for a large fraction of impressionable voters is that, given rational behavior of voters in the model, fiscal manipulation is less effective to "buy" the vote of any single individual precisely in the cases where there are more swing voters. In this simplified setting, where our assumptions imply that the probability of re-election $\rho\left(g_{1}\right)$ is either 0 or 1 , this is reflected in the fact that $\bar{p}_{1}\left(T \mid \phi_{I}+\phi_{M}<\frac{1}{2}\right)=1 \geq \bar{p}_{1}\left(T \mid \phi_{I}+\phi_{M} \geq \frac{1}{2}\right)$.

Note further that the assumption that $\bar{\omega}=\infty$ (and the implication that a fiscal expansion in an election year reflects mimicking by the $\underline{\omega}$ politician, whom voters would not prefer if his type were known) is a convenient modeling device, rather than essential to the existence of the political cycle. Were $\bar{\omega}<\infty$, a cycle might take the form of signaling, in that the $\underline{\omega}$ type would choose $\underline{g}$ in both election and non-election periods, while the $\bar{\omega}$ type would choose $g_{1}$ just high enough to separate himself in an election period. If this is higher than the $g_{2}$ he would choose in a non-election period, we have the same type of cycle qualitatively. This latter strategy is the one chosen by Rogoff (1990), in a model of signaling of competence. Rogoff's approach has been criticized (unfairly, we think)

\footnotetext{
${ }^{10}$ The unconditional expectation value of targeted expenditure is given by $E\left(g_{1}\right)=T\left[\bar{p}+(1-\bar{p}) \operatorname{Pr}\left(g_{1}=T \mid \underline{\omega}\right)\right]+$ $\underline{g}(1-\bar{p}) \operatorname{Pr}\left(g_{1}=\underline{g} \mid \underline{\omega}\right)$ in an election period, and $E\left(g_{2}\right)=T \bar{p}+\underline{g}(1-\bar{p})$ in non-election period.
} 
in that it is the more competent candidate the one who engages in fiscal manipulation. One could model the competence problem as one where the less competent may want to mimic the other type, implying that the less desirable candidate is the one who engages in fiscal manipulation.

\subsection{Asymmetric information about the electoral environment}

So far, we have assumed $\phi_{I}, \phi_{M}$, and $\phi_{C}$ are common knowledge, in that the distribution of voter types is known both to voters and politicians. This assumption is clearly not realistic, as the electoral effectiveness of providing targeted spending to voters is not known with certainty, and candidates frequently have better information about it than the public does. We now relax this assumption, and show that the existence of asymmetric information about the political environment reinforces the incentives faced by incumbent officials to affect election outcomes through changes in fiscal policy. Introducing asymmetric information about political characteristics of voters will also eliminate the unsatisfactory feature that in some of the equilibria with electorally-motivated expenditures (more exactly in the pooling equilibrium), voters are indifferent between the challenger and the incumbent who targets them with spending. This is of course a result of our simplifying assumptions, so we do not take it as a prediction of the model that voters will strictly be indifferent. However, it does open the question of how do individuals actually vote when they are "indifferent", since one would not expect them to simply toss a coin to define which candidate to support.

We now assume that candidates running for election know more than voters about the effectiveness of targeted expenditures to generate votes. In our simple setting, we can account for this type of information asymmetry by assuming that the shares of core and swing voters are only known to the politician. In particular, we assume that voters assign a probability $z$ that $\phi_{C}<\frac{1}{2}$. In other words, voters assign a probability $1-z$ that the challenger's core voters are a majority, in which case a desks-type incumbent would have no incentive to choose $g_{1}=T$.

Voters now characterize the incumbent's behavior by

$$
\operatorname{Pr}\left(g_{1}=T\right)=\bar{p}+z(1-\bar{p}) \operatorname{Pr}\left(g_{1} \mid \omega=\underline{\omega}, \phi_{C}<\frac{1}{2}\right)
$$

since in the event the politician is of the desks-type (with associated prior probability $1-\bar{p}$ ), he would choose $g_{1}=T$ only if $\phi_{C}<\frac{1}{2}$, which happens with probability $z$. After observing fiscal policy, voters update their beliefs about the incumbent's type following Bayes' rule, as captured by equation 
(9). Their posterior beliefs on the probability that a policymaker who chooses high expenditures is of the high type are now:

$$
\bar{p}_{1}\left(g_{1}=T\right) \equiv \operatorname{Pr}\left(\omega=\bar{\omega} \mid g_{1}=T\right)=\frac{\bar{p}}{\bar{p}+z(1-\bar{p}) \operatorname{Pr}\left(g_{1} \mid \omega=\underline{\omega}, \phi_{C}<\frac{1}{2}\right)}
$$

Given $z<1$, it is now the case that $\bar{p}_{1}\left(g_{1}=T\right)>\bar{p}$ even if $\operatorname{Pr}\left(g_{1} \mid \omega=\underline{\omega}, \phi_{C}<\frac{1}{2}\right)=1$. That is, the incumbent can lead swing voters to prefer him over the challenger by choosing high targeted expenditures, even if a desks-type politician is as likely to choose high election-year targeted expenditures as a people-type politicians whenever $\phi_{C}<\frac{1}{2}$. The reason is simply that voters do not know whether the latter holds.

The equilibria for this case are described in Proposition 2:

Proposition 2 (Asymmetric Information about Voter's Preferences) In equilibrium, the optimal strategy for a swing voter is to vote for the incumbent with probability $r\left(g_{1}\right)=\left\{\begin{array}{l}1 \text { if } g_{1}=T \\ 0 \text { otherwise }\end{array}\right\}$. The optimal strategy for the desks-type incumbent is $\operatorname{Pr}\left(g_{t}=T \mid \phi_{C}\right)=q\left(\phi_{C}\right)$. If $\phi_{C} \geq \frac{1}{2}$ then $q\left(\phi_{C}\right)=0$. If $\phi_{C}<\frac{1}{2}$ then $q\left(\phi_{C}\right)\left\{\begin{array}{c}=1 \text { if } \beta(\bar{p} \Delta \Omega+\chi)>\Delta \Omega \\ =0 \text { if } \beta(\bar{p} \Delta \Omega+\chi)<\Delta \Omega \\ \in[0,1) \text { if } \beta(\bar{p} \Delta \Omega+\chi)=\Delta \Omega\end{array}\right\}$.

This type of imperfect information makes the problem more interesting, by capturing an additional inference problem for voters. Voters need to make inferences about whether they are being targeted with spending because the politician prefers such expenditures, or because they are very effective to get votes. The fact that they assign some probability that the latter is not true gives more room for the politician to influence the outcome of elections by providing more targeted expenditures prior to elections.

\section{Some Empirical Evidence: Local Finances in Colombia}

In this section, we present empirical evidence supporting the ideas presented in section 2 . The model has two basic predictions. Lemma 1 states that fiscal manipulation may take the form of changes in the composition of spending when voters are averse to deficits. Our data offer a higher level of disaggregation than earlier studies, allowing a closer look at the composition issue. Moreover, the conceptual framework provided by our model facilitates a more systematic analysis 
of the different categories of spending. Lemma 2 considers the response of voters to pre-election changes in budget composition. Hence, we present empirical evidence not only on how elections affect budget composition, but also on how vote shares respond to these changes.

\subsection{The pre-election composition of government expenditure}

We concentrate first on the election-year changes in fiscal policy. The model indicates that targeted spending should rise preceding an election, while other types of spending should contract. We therefore try to find evidence of pre-election increases in categories of expenditure that most likely reflect targeted spending, accompanied by contractions in other categories.

The difference between targeted and non-targeted spending is obviously hard to identify in the data. However, opportunistic targeted expenditures, often known as pork barrel spending, are most often associated in Colombia with infrastructure development projects: construction of roads, schools, water plants. Projects of this type are highly visible and benefit specific (yet potentially large) groups of voters. On the other hand, some current expenditures, such as purchases of supplies and services, payments to other government agencies, and debt service, can be presumably cut without visibly hurting large groups of voters. Hence, given the predictions of our model, we would expect pre-election increases in those categories of spending that capture development projects, and cuts in at least some categories of current spending.

Testing these hypotheses requires data on different types of government expenditures, covering observations in both election and non-election years. We compiled a panel of data on government accounts and electoral outcomes for all municipalities in Colombia (close to 1100 cross-sectional units) over the period 1987 to 2000. A unique feature of our data compared to those used in previous studies is the high level of disaggregation of expenditures, allowing us to distinguish different types of spending. From the point of view of the study of fiscal policy in Colombia, the data are also novel in incorporating electoral outcomes. A much more detail description of the data can be found in Eslava (2004).

We choose this "cross-district" approach in a single country, rather than the more usual crosscountry strategy for two reasons. First, the political budget cycle effects we propose are most relevant at the local level, where spending can be targeted most efficiently. Second, the cross sectional variability of institutions is much harder to take into account in a multi-country setting than it is 
for cross sectional units within the same country. Constitutional rules, national laws, electoral and judicial systems, monetary policy, are all important determinants of the existence and strength of political budget cycles. These characteristics vary far more across countries than in districts within the same country, which share all of the above-mentioned institutional characteristics. ${ }^{11}$

Though the direct re-election of incumbent executive officials is banned in Colombia, electoral manipulation of fiscal policy is regarded as a usual political practice. Political budget cycles are thought to arise in Colombia largely due to the actions of the legislative bodies, whose members are in fact subject of direct re-election (in the case of city councils), or at least have found ways to circumvent formal restrictions to run for direct re-election (as in the national Congress). Moreover, there are two reasons why an incumbent mayor who cannot run for re-election has incentives to manipulate fiscal policy at the end of his term of office. First, an incumbent knows that his decisions affect his party's re-election chances (or those of the incumbent's preferred candidate). Second, officials usually run for election to other posts in later years, or for re-election to the same post in the future, and their actions while in office are used by voters in future elections to assess their preferences and competence.

Following much of the literature, we estimate equations in which the policy variables are represented as functions of the timing of elections, as well as other controls. The basic relationship can be written as:

$$
f_{i t}=a_{i}+b_{1} f_{i t-1}+b_{2} f_{i t-2}+\sum_{k} c_{k} x_{k, i t}+d \cdot \text { elecdum }_{i t}+\varepsilon_{i t}
$$

where $f$ is a fiscal policy variable, $a_{i}$ is a district effect, the $x$ are control variables, and $i$ is an index for the district. The variable elecdum, a political dummy which captures the timing of elections, is the central variable of our analysis. It takes the value of one in periods preceding local elections, and 0 in all other periods. We time this dummy such that the pre-election period is the year previous to the election if the election takes place in the first half of the year, and the year of the election, if the election is held in the second half. The autoregressive form is used in the literature on political cycles as a parsimonious representation of policy choices. We include additional controls to account for as much variability in the data as we can.

We estimate a separate regression for (the log of) each type of government expenditure. That is,

\footnotetext{
${ }^{11}$ Alesina (2005) presents a number of studies of the political economy of Colombia which may serve as useful background.
} 
each type of government expenditure is a different $f$. In all regressions, we are interested in $d$, the coefficient that captures the effect of elections. Of the 18 years in our sample, 6 are local election years, when mayors, and city councils are elected. Elections occur at predetermined dates. Table 2 contains a list of elections held between 1987 and $2000 .^{12}$

\subsubsection{Data}

We briefly present now the data we use. A more detailed description can be found in Eslava (2004).

In terms of dependent variables, as mentioned above, we want to estimate 13 for different components of public expenditure. We use data from the Colombian Contraloría General, a public agency with the task of monitoring public finances. Our data correspond to the figures in the financial report each municipality files with the Contraloría annually. The general structure of the expenditure accounts, as well as basic statistics, are summarized in Table 1.

We estimate (13) using each of the expenditure categories mentioned in Table 1 as dependent variables. That is, we run a separate regression for each category of spending. Besides the categories listed in Table 1, we also examine investment in roads, which is a subcomponent of infrastructure investment, ${ }^{13}$ and some subcomponents of personnel payments and current transfers. As mentioned before, we expect to find pre-election expansions in the components closely related to development projects such as infrastructure, water, power and communications, and road construction.

For each type of expenditure, Figures $1 \mathrm{a}$ and $1 \mathrm{~b}$ show mean values - in hundreds of thousands of 1998 pesos - for election and non-election years. Notice that in general current expenditure categories have lower averages in election periods that in other periods. The opposite happens for investment categories. While these observations suggest pre-election effects in the direction we expect, more systematic evidence is obtained by estimating equation (13).

One should note that "Current Transfers", as defined in the Colombian government accounts, refer to benefits to retired and temporary employees, and transfers to other levels of government, groups that are unlikely to be the targets of election-year spending. They do not correspond to the kind of transfers to specific groups that are often central to electoral manipulation. As argued

\footnotetext{
${ }^{12}$ Our period of estimation begins in 1987 because mayors are elected by popular vote only since 1988. However, we have data on all variables starting in 1984. These additional observations allow us to estimate (13) in differences and use lags of the regressors as instruments (see an explanation of estimation strategy below) without loosing observations.

13 "Infrastructure" includes, besides the construction of roads, urban infrastructure and construction of market places.
} 
above, in the Colombian government accounts, election-year opportunistic spending is more likely captured by some investment categories.

Table 3 lists the different controls we use in alternative specifications. We use different specifications, with alternative sets of controls, to analyze the robustness of our results. Our controls include per capita GDP to account for economic activity, a time trend, and some social indicators that could be used as inputs in fiscal policy decisions. The latter include population and a poverty indicator known as "Unsatisfied Basic Needs". We also use alternative financial indicators as controls, trying to account for some constraints faced by the government. These are particularly important in later years, when the law has required that regional governments in Colombia obtain authorization from the central level to increase expenditure if they have been running deficits in previous years. We use deficit, debt, and fiscal dependence indicators, which we constructed by us from the Contraloría data. The Fiscal Dependence indicator accounts for the degree of fiscal decentralization at the national level, which grew dramatically over this period. The indicator is increasing in the share of revenues represented by transfers from the central government (as opposed to the local government's own fiscal effort). We interact it with the trend variable, to differentiate the trend effects related to the process of fiscal decentralization from any other trend effects. Finally, we include Incumbent Advantage, measured by the percentage share of votes received by the incumbent in the last election. We try to account in this way for the greater degrees of freedom that a popular incumbent has when choosing fiscal policy. ${ }^{14}$

\subsubsection{Estimation strategy}

Given the presence of the city-specific effects, $a_{i}$, we estimate (13) in differences. Since this differentiation introduces endogeneity problems, estimation is done by $\mathrm{GMM}^{15}$ using $f_{i, t-s-1}$ and $f_{i, t-s-2}$ to

\footnotetext{
${ }^{14}$ The GDP per capita data are from DANE (the Colombian Bureau of Statistics), while population and the Unsatisfied Basic Needs indicator were provided by the University of Los Andes' CEDE. Deficit, Debt, and Fiscal Dependence were constructed by us from the Contraloría data. As for Incumbent Advantage, we use electoral results recorded in the National Planning Department Databases for the pre-1997 elections, while for 1997 and 2000 we use official results directly provided by the Registraduría Nacional. More details on the construction of all these controls can be found in Eslava (2004).

${ }^{15}$ A detailed discussion of the endogeneity problems in this estimation, as well as the virtues of the estimation technique used can be found in Eslava (2004). It should be noted that the most widely used methodology in this literature is the one suggested by Arellano and Bond (1991). We do not use this approach because, with the relatively large numbers of periods (15) and endogenous variables (up to 5) in our estimations, the Arellano-Bond estimation contains more than 60 instruments. GMM estimators with such a large number of overidentifying restrictions are known to have poor finite sample properties. Our results are, however, robust to the use of Arellano-Bond techniques, although the set of instruments does not perform as well as under the methodology we use here. Results of Arellano-
} 
instrument for the $\Delta f_{i, t-s}=f_{i, t-s}-f_{i, t-s-1}$, and $x_{i, t-s-1}$ and $x_{i, t-s-2}$ to instrument for the $\Delta x_{i, t-s}$.

The following sequential endogeneity constraints guarantee the validity of these instruments:

$$
E\left(\varepsilon_{i t} f_{i t-s}\right)=0 \text { for all } t \text { and for } s \geq 1
$$

The electoral dummy is assumed strictly exogenous with respect to the error term, since the timing of elections is pre-determined in Colombia. That is,

$$
E\left(\varepsilon_{i t} e l e c d u m_{i v}\right)=0 \text { for all } v, t
$$

Other controls are in general assumed to be sequentially exogenous, although some of them may be contemporaneously correlated with the error term. ${ }^{16}$ The general assumptions are:

$$
E\left(\varepsilon_{i t} x_{i t-w}\right)=0 \text { for all } t \text { and for } w \geq \bar{a}
$$

where $\bar{a}=0$ for control variables assumed not contemporaneously correlated with the error term, and $\bar{a}=1$ for the opposite case.

\subsubsection{Results}

Results for the political dummy $d$ in which we are interested are presented in Table $4 .{ }^{17}$ In the table, each of columns (1) through (4) represents a different set of controls, as detailed in Table 3. Each row corresponds to a different regression, with the dependent variable for each regression given in the first column. For instance, the first row reports the estimate of $d$ when the dependent variable is the log of current expenditure. (All dependent variables are expressed in logs.) Results in bold letters are significant at the $5 \%$ level, in bold and italics significant at the $10 \%$ level.

Results point to an election-year change in the composition of spending in the expected direction. We observe a decrease in some current expenditures before elections, specifically transfers to retirees, payments to temporary workers, and payments of debt service. Concurrent with this contraction

Bond estimations of our model are presented briefly in Eslava (2004).

${ }^{16}$ Incumbent advantage, the time trend, the fiscal dependence indicator (since it is an aggregate-level indicator), and previous year's deficit and debt are all assumed contemporaneously exogenous with respect to the error term. The rest of controls are assumed potentially correlated with the contemporaneous error term.

${ }^{17}$ To facilitate reading, estimates for other coefficients are not reported. All other results are available from the authors upon request, and some of them are reported in Eslava(2004). 
we find an increase of spending in development projects. In particular, total investment and its subcategories infrastructure, power and road construction all show pre-election increases. Interestingly, payments to permanent workers appear to increase prior to elections. ${ }^{18}$ These changes in spending are not only statistically significant, but also large in size. For instance, current transfers fall close to $30 \%$ and interest payments close to $10 \%$, while total investment rises about $15 \%$ before elections. ${ }^{19}$

A similar message emerges if the dependent variables are the shares of total expenditure represented by each category (Table 5). While the fraction of current expenditures and interest payments in total spending decreases before elections, the opposite occurs with investment. The reduction of current spending is explained mainly by lower transfers to retirees and payments to temporary workers. On the other hand, the investment category that rises before elections is infrastructure, including road construction, and construction of power and water plants.

In summary, we find that before elections the composition of local government expenditures changes in a systematic way. There is a shift of resources away from what we believe to be less popular types of spending into development projects, which may represent spending clearly targeted to voters. One is then led to ask whether such compositional changes actually change voting patterns in favor of the incumbent. We now turn to empirical evidence on the link between the government's budget and election outcomes.

\section{$3.2 \quad$ Voting}

Our approach has two broad implications about voter response to electoral fiscal policy. First (which is actually an assumption), voters dislike deficits. Second, and most importantly, different categories of spending have differential effects on voting, with the incumbent deriving the most electoral benefit from "targeted" expenditures. In this section, we address these points empirically.

\footnotetext{
${ }^{18}$ The finding of a pre-electoral expansion of personnel expenditures would be consistent with the widespread idea that politicians in Colombia trade government jobs in exchange for political support.

${ }^{19}$ Table 4 does not include the effect on total spending. The reason is that the model presented above makes no prediction regarding total expenditure. In this approach, the effect on total spending is seen simply as the sum of what happens to individual categories. It is worth mentioning, however, that by estimating (13) with $f$ equal to the $\log$ of total expenditure, one obtains a very small pre-electoral effect. Although in specifications 1 and 3 it is statistically significant, it is only approximately $3 \%$. Moreover, in specifications 2 and 4 it is not even statistically significant.
} 


\subsubsection{Data}

The relevant definition of "incumbent" for the Colombian case is the incumbent party, since officials cannot run for direct re-election. We therefore use data on the share of votes obtained by each party in local mayoral elections from 1992 to 2000 (four elections). ${ }^{20}$

Politics in Colombia have been traditionally dominated by two major parties, Liberal and Conservative. While some candidates, particularly in the 1990's, ran under the banner of a myriad of different parties or political movements, many of these movements can be traced back to the traditional parties, and voters in each locality are frequently aware of those ties. In that sense, elections are still mainly a contest between these two major parties, although there are also two smaller left-wing parties and some truly independent political groups.

Given these political groupings, one challenge in the data is to identify which candidates are associated with one of the major parties, in order to calculate the appropriate shares of party votes. We use information from external sources to match the different movements with the traditional party division between Liberals and Conservatives. Movements that were not successfully linked to one of the main parties are considered "independents" in our analysis. We calculate the share of votes obtained by the Liberal party, for example, as the sum of the shares obtained by all the smaller organizations linked to the Liberal party. It is important to highlight that there is measurement error due to the difficulty in identifying some matches (in particular, some organizations linked to one of the parties may have been mistakenly assigned as independents). More details on the construction of these linkages can be found in Eslava (2004).

\subsubsection{The effect of fiscal policy on vote shares}

Vote shares are modeled as a function of the fiscal choices of the incumbent party in the pre-election period. Following the literature on voters as fiscal conservatives (e.g., Peltzman [1992], Brender [2003]), we consider the effect of deficits on vote shares. We also attempt to distinguish the effects of different spending categories, given that our theoretical results suggest that voters see targeted expenditures differently than the rest of spending. Following the previous discussion, we treat investment spending as targeted expenditure, and current spending as non-targeted expenditure.

\footnotetext{
${ }^{20}$ Unfortunately, for previous elections only the share of votes obtained by the winner of the election is available, so that full party shares cannot be calculated.
} 
We run a regression of the following form:

$$
\begin{aligned}
\text { votes }_{\text {pis }} & =\alpha_{0}+\alpha_{1} \text { votes }_{\text {pis }-1}+\alpha_{2} \text { invest }_{i s}+\alpha_{3} \text { current }_{i s}+\alpha_{4} \text { deficit }_{i s}+\alpha_{5} \text { gr }_{i s} \\
& +\left(\beta_{2} \text { invest }_{i s}+\beta_{3} \text { current }_{i s}+\beta_{4} \text { deficit }_{i s}+\beta_{5} \text { gr }_{i s}\right) * i n c_{p i s-1}+v_{i s p}
\end{aligned}
$$

The time indices, $s$, refer to election periods, so that $s$ is the current election and $s-1$ the previous election. votes $s_{\text {pis }}$ is the share (in percentages) of votes obtained by party $p$ in city $i$ in the election at $s$. The fiscal variables correspond to the election year (as defined above); we include the log of per capita investment spending (invest ${ }_{i s}$ ), the log of per capita current spending ( current $_{i s}$ ), and the per capita government deficit $\left(\right.$ deficit $\left._{i t}\right)$. The discrete variable $i n c_{p i s-1}$ takes a value of 1 if the party $p$ is in power before the election, and 0 otherwise. Average GDP growth between $t-1$ and $t\left(g r_{i t}\right)$ is also considered to control for other observables that may affect voters' perceptions about the incumbent. The direction of the results reported below is robust to changing the specification to one that restricts the effect of fiscal policy on the votes received by the incumbent to be the negative of its effect on the votes received by the challenger (see Eslava [2004]).

We interpret the coefficients $\beta_{2}, \beta_{3}, \beta_{4}$ as reflecting the advantage (or disadvantage) the incumbent obtains with respect to the challenger for increasing investment, current spending or the deficit before the election. Under the assumption that $v_{i t p}$ captures the part of voting behavior that the politician cannot predict, fiscal policy decisions cannot be based on those innovations, and the policy variables included in the regression should satisfy the restriction of being orthogonal to the error term. Assuming that there are no components of $v_{i t}$ that affect the incumbent's fiscal choices may indeed be strong, but data restrictions make addressing these concerns a quite difficult task, beyond the scope of this paper.

Results are reported in Table 6; column (1) reports estimates of (14), while column (2) reports results of a slightly modified version that includes party/state effects. ${ }^{21}$ Robust standard errors are reported below the point estimates. Column (3) reports results of specification (14), but the spending variable invest is measured as a fraction of total spending (in this case, the corresponding fraction for current spending is not included in the specification due to concerns about collinearity of the regressors).

\footnotetext{
${ }^{21} \mathrm{~A}$ full fixed-effects version cannot be used due to restrictions of the voting shares data: for most localities we have no more than 1 usable observation.
} 
As previous studies have found for other countries (e.g. Peltzman [1992] for the U.S., Brender [2003] for Israel, Brender and Drazen [2005] for developed countries in general), and contrary to the implicit view in much of the empirical literature on political budget cycles, the results indicate that Colombian voters penalize the incumbent party for running high deficits. Furthermore, high capital expenditures (interpreted here as targeted spending) increase the share of votes obtained by the incumbent party relative to the challenger, while current ("non-targeted") expenditure has no significant effect. ${ }^{22}$ From column (3), for instance, a ten percent increase in the share of spending dedicated to investment increases the fraction of votes obtained by the incumbent party by about $1 \%$, while a two standard deviation increase in the deficit per capita decreases the share of votes to the incumbent party by close to $4.2 \%$. These results are consistent with the view that voters dislike incumbents who run high deficits, while they value specific types of expenditures. They are also consistent with the results on electoral changes in the composition of spending discussed above which show incumbents increasing targeted spending before the elections, while they try to avoid concomitant increases in the overall budget.

\section{Conclusions}

This paper presents a view of the Political Budget Cycle in which voters may dislike fiscal deficits, even though they value government spending on some specific types of goods. Politicians are aware of voter preferences (which may differ from their own), and hence electoral manipulation of the budget takes the form of a change in the composition of expenditure from less to more targeted spending, rather than an increase in the overall size of the budget. We present a model with perfectly rational, forward-looking voters, who use the provision of public goods to make inferences about the incumbent's fiscal preferences. Election-year shifts of the budget improve the incumbent's chances of being re-elected, since voters assign some probability that more targeted spending reflects a the incumbent's true preference for types of spending voters prefer, rather than purely electoral incentives.

The predictions of our model are shown to be consistent with evidence on the composition of public spending and the behavior of voters in Colombian municipalities. We find that, prior

\footnotetext{
${ }^{22}$ Tests of joint significance indicate that $\alpha_{2}+\beta_{2}$ (the "absolute" effect of investment on the share of votes received by the incumbent) is positive and statistically significant, $\alpha_{3}+\beta_{3}$ is not significantly different from 0 , and $\alpha_{4}+\beta_{4}$ is negative and significant.
} 
to elections, some components of spending that we believe are particularly attractive to voters expand significantly. These components are infrastructure spending, including road construction and construction of power and water plants. On the other hand, interest payments, transfers to retirees, and payments to temporary workers contract in election years. We also find that voters penalize the incumbent party for running large deficits before elections, and reward it for increasing the amount of targeted spending observed before the election. 


\section{References}

Akhmedov, A. and Zhuravskaya, E. (2004), "Opportunistic Political Cycles: Test in a Young Democracy Setting," Quarterly Journal of Economics 119, 1301-38.

Alesina, A., editor (2005), Institutional Reforms: The Case of Colombia, Cambridge, MA: MIT Press.

Alesina, A., R. Perotti and Tavares (1998), "The Political Economy of Fiscal Adjustments," Brookings Papers on Economic Activity 1:1998.

Brender, A. (2003), "The Effect of Fiscal Performance on Local Government Election Results in Israel: 1989-1998," Journal of Public Economics 87, 2187-2205.

Brender, A. and A. Drazen (2004), "Political Budget Cycles in New Versus Established Democracies," NBER Working Paper 10539. (Latest version available at http://www.tau.ac.il/ drazen) in progress.

(2005), "How Do Budget Deficits and Economic Performance Affect Reelection Prospects?,"

Dixit, A. and J. Londregan (1996), "The Determinants of Success of Special Interests in Redistributive Politics," Journal of Politics 58, 1132-55.

Drazen, A. and M. Eslava (2005), "Political Budget Cycles When Politicians Have Favorites," working paper, University of Maryland.

Eslava, M. (2004) "Political Budget Cycles or Voters as Fiscal Conservatives? Evidence from the Colombian Experience," Mimeo, Universidad de Los Andes.

Gonzalez, M.(1999), "Political Budget Cycles and Democracy: A Multi-Country Analysis," working paper, Department of Economics, Princeton University.

Gonzalez, M.(2002), "Do Changes in Democracy Affect the Political Budget Cycle? Evidence from Mexico," Review of Development Economics 6, 204-224.

Kneebone, R. and McKenzie, K. (2001) "Electoral and Partisan Cycles in Fiscal Policy: an Examination of Canadian Provinces," International Tax and Public Finance 8, 753-774.

Lindbeck, A. and J. Weibull (1987), "Balanced Budget Redistribution as the Outcome of Political Competition," Public Choice 52, 272-97.

Peltzman, S. (1992), "Voters as Fiscal Conservatives," Quarterly Journal of Economics 107, 327-261

Persson and Tabellini (2003), The Economic Effect of Constitutions: What Do the Data Say?, Cambridge, MA: MIT Press.

Rogoff, K. (1990), "Equilibrium Political Budget Cycles," American Economic Review 80, 21-36.

Rogoff, K. and A. Sibert (1988), "Elections and Macroeconomic Policy Cycles," Review of Economic Studies 55, 1-16.

Shi, M. and J. Svensson (2002a), "Conditional Political Budget Cycles," CEPR Discussion Paper \#3352.

(2002b) "Political Business Cycles in Developed and Developing Countries," working paper. 
Table 1. Summary statistics for different types of expenditure

\begin{tabular}{|c|c|c|c|}
\hline Type of Expenditure & Number of obs. & Mean & $\begin{array}{l}\text { Standard } \\
\text { deviation }\end{array}$ \\
\hline Total Expenditure & 12,335 & 56,458 & 611,226 \\
\hline 1. Current Expenditure & 12,334 & 19,856 & 185,433 \\
\hline 1.1. General Payments & 12,265 & 4,068 & 21,005 \\
\hline 1.2. Personnel Exp. & 12,266 & 9,759 & 82,677 \\
\hline 1.3. Current Transfers & 12,247 & 5,895 & 91,341 \\
\hline 2. Investment & 12,335 & 30,129 & 382,126 \\
\hline 2.1. Infrastructure & 5,276 & 3,173 & 8,252 \\
\hline $\begin{array}{l}\text { 2.2. Water, Energy, and } \\
\text { Comunications }\end{array}$ & 5,571 & 3,707 & 6,166 \\
\hline 2.3. Housing & 7,365 & 761 & 4,069 \\
\hline 2.4. Education & 7,469 & 3,615 & 5,523 \\
\hline 2.5. Health & 7,469 & 2,710 & 5,007 \\
\hline \multicolumn{4}{|l|}{ 2.6. Other } \\
\hline 3. Debt service & 12,186 & 6,554 & 70,578 \\
\hline
\end{tabular}

All measures in hundreds of pesos of 1998 
Figure 1a: Current Spending: Election vs. Non-Election Years

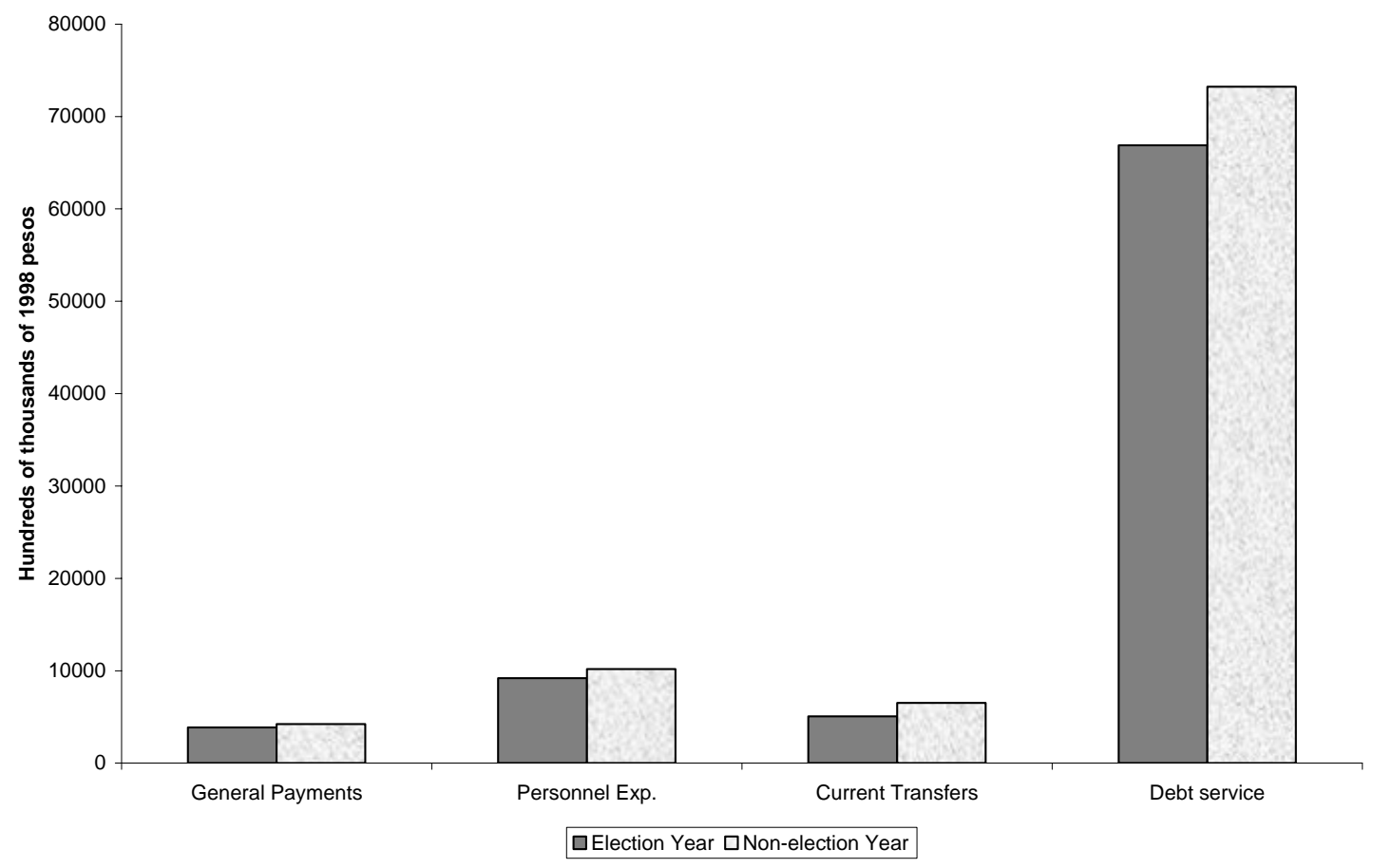

Figure 1b: Investment Spending: Election vs. Non-Election Years

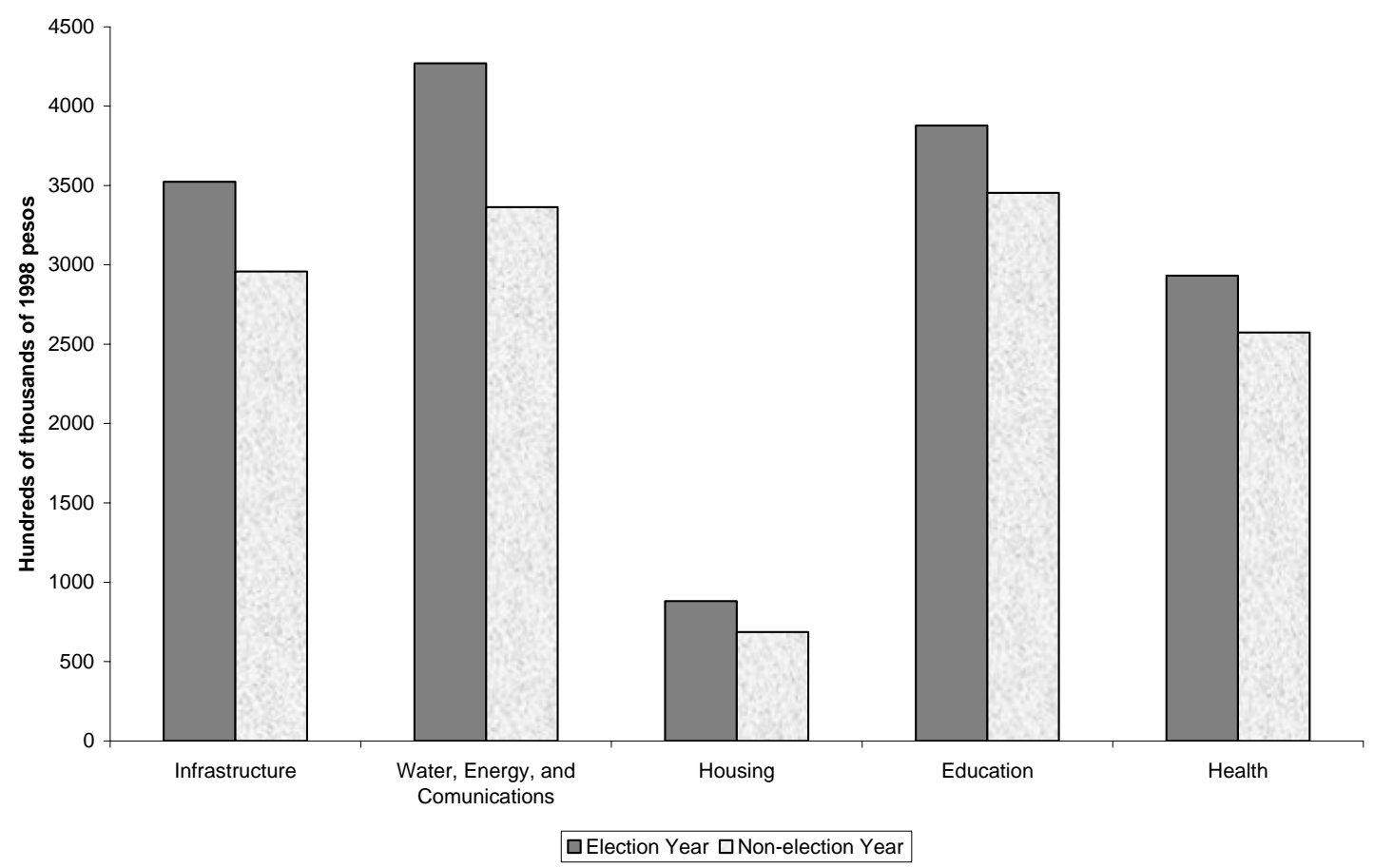


Table 2.

Dates of elections for mayor

\begin{tabular}{cc}
\hline \hline Election & elecdum=1 in: \\
\hline March 1988 & 1987 \\
March 1990 & 1989 \\
March 1992 & 1991 \\
October 1994 & 1994 \\
October 1997 & 1997 \\
October 2000 & 2000 \\
\hline
\end{tabular}

Table 3. List of control variables

\begin{tabular}{|c|c|c|c|c|}
\hline \multirow{2}{*}{ Control } & \multicolumn{4}{|c|}{ Specification } \\
\hline & 1 & 2 & 3 & 4 \\
\hline $\mathrm{T}(\mathrm{t})$ & $x$ & $x$ & $x$ & $\mathrm{x}$ \\
\hline$y(i, t-1)$ & $x$ & $x$ & $x$ & $x$ \\
\hline log_GDP_PC(i,t-1) & $x$ & $x$ & $x$ & $x$ \\
\hline log_UBN(i,t-1) & $x$ & $x$ & $x$ & $x$ \\
\hline log_POPULATION(i,t-1) & $x$ & $x$ & $x$ & $\mathrm{x}$ \\
\hline DEFICIT(i,t-1) & & $x$ & & $\mathrm{x}$ \\
\hline DEBT_84(i,t-1) & & & $x$ & \\
\hline$T^{\star}$ FISCAL_DEP(t) & & $x$ & $x$ & $x$ \\
\hline VOTE SHARE(i, prev.elect) & & & & $\mathrm{x}$ \\
\hline
\end{tabular}


Table 4.

Effect of elections on different types of expenditure (levels)

Dependent Variable: Type of expenditure

\section{Current Expenditure}

1.1. General Payments

1.2. Personnel Expenditure

1.2.1 Personnel Temporary

1.3. Current Transfers

1.3.1 Transfers to retired workers

1.3.2. Other Transfers

2. Investment

2.1. Infrastructure

2.1.1. Roads

2.2. Water, Energy, and Com

2.3. Housing

2.4. Education

2.5. Health

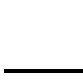

1

$-0.024$

(0.024)

0.037

(0.027)

0.071

(0.012)

$-0.546$

$(0.252)$

$-0.222$

(0.082)

$-0.977$

$(0.470)$

0.043

(0.125)

0.142

(0.025)

$\mathbf{0 . 4 3 6}$

(0.072)

0.365

(0.069)

$\mathbf{0 . 2 1 9}$

(0.065)

0.124

(0.207)

0.110

(0.027)

0.084

(0.054)

\section{$-0.053$}

(0.031)

2

$-0.033$

(0.018)

0.025

(0.043)

$\mathbf{0 . 0 8 2}$

(0.020)

$-0.371$

(0.106)

$-0.369$

(0.101)

$-0.826$

(0.437)

0.324

(0.159)

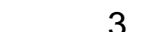

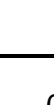

$-0.011$

(0.019)

0.031

(0.041)

0.087

(0.019)

$-0.303$

(0.100)

$-0.270$

(0.078)

$-1.236$

(0.575)

0.247

(0.150)

$\mathbf{0 . 1 2 6}$

(0.027)

0.144

(0.028)

0.507

(0.098)

(0.077)

0.392

(0.076)

0.412

(0.074)

0.193

(0.077)

0.100

(0.228)

$\mathbf{0 . 0 9 0}$

(0.032)

(0.032)

0.097

(0.064)

0.079

(0.061)

$-0.104$

(0.038)

(0.036)
4

$-0.041$

(0.023)

0.032

(0.051)

$\mathbf{0 . 0 8 4}$

(0.022)

$-0.369$

(0.109)

$-0.332$

(0.123)

$-0.659$

$(0.396)$

0.398

(0.162)

0.122

(0.028)

0.376

(0.083)

0.318

(0.078)

0.177

(0.075)

0.432

(0.212)

$\mathbf{0 . 0 9 0}$

$(0.034)$

0.128

(0.070)

\section{Debt Service}

This is a GMM estimation of equation 13. Standard errors in parenthesis.
Estimate is significant at $5 \%$ level if in bold characters, at $10 \%$ if in bold and italics.

$-0.090$

Each row corresponds to a different regression, where the dependent variable is

the level of expenditure in each category.

Each column corresponds to a different set of controls, as detailed in table 2 
Table 5.

Effect of elections on the composition of total expenditure (shares)

\begin{tabular}{|c|c|c|c|c|}
\hline $\begin{array}{l}\text { Dependent Variable: Type of } \\
\text { expenditure }\end{array}$ & 1 & 2 & 3 & 4 \\
\hline \multirow[t]{2}{*}{ 1. Current Expenditure } & -0.088 & -0.081 & -0.070 & -0.079 \\
\hline & $(0.013)$ & $(0.016)$ & $(0.019)$ & $(0.015)$ \\
\hline \multirow[t]{2}{*}{ 1.1. General Payments } & -0.041 & -0.001 & 0.006 & 0.016 \\
\hline & $(0.031)$ & $(0.043)$ & (0.045) & $(0.051)$ \\
\hline \multirow[t]{2}{*}{ 1.2. Personnel Expenditure } & 0.038 & 0.037 & 0.061 & 0.038 \\
\hline & (0.018) & $(0.032)$ & $(0.028)$ & $(0.035)$ \\
\hline \multirow[t]{2}{*}{ 1.2.1 Personnel Temporary } & -0.466 & -0.319 & -0.206 & -0.321 \\
\hline & $(0.282)$ & $(0.159)$ & $(0.146)$ & $(0.160)$ \\
\hline \multirow[t]{2}{*}{ 1.3. Current Transfers } & -0.286 & -0.444 & -0.356 & -0.418 \\
\hline & $(0.060)$ & $(0.070)$ & $(0.070)$ & $(0.082)$ \\
\hline \multirow{2}{*}{$\begin{array}{l}\text { 1.3.1 Transfers to retired } \\
\text { workers }\end{array}$} & -0.978 & -0.849 & -1.501 & -0.688 \\
\hline & $(0.508)$ & $(0.403)$ & $(0.591)$ & $(0.364)$ \\
\hline \multirow[t]{2}{*}{ 1.3.2. Other Transfers } & -0.060 & 0.277 & 0.183 & 0.347 \\
\hline & $(0.118)$ & $(0.162)$ & $(0.147)$ & $(0.163)$ \\
\hline \multirow[t]{2}{*}{ 2. Investment } & 0.106 & 0.075 & 0.081 & 0.080 \\
\hline & $(0.019)$ & $(0.025)$ & $(0.022)$ & $(0.025)$ \\
\hline \multirow[t]{2}{*}{ 2.1. Infrastructure } & 0.421 & 0.413 & 0.382 & 0.361 \\
\hline & $(0.087)$ & $(0.097)$ & $(0.107)$ & $(0.117)$ \\
\hline \multirow[t]{2}{*}{ 2.1.1. Roads } & 0.401 & 0.377 & 0.394 & 0.350 \\
\hline & $(0.065)$ & $(0.074)$ & $(0.066)$ & $(0.085)$ \\
\hline \multirow[t]{2}{*}{ 2.2. Water, Energy, and Com. } & 0.187 & 0.138 & 0.142 & 0.166 \\
\hline & $(0.074)$ & $(0.081)$ & $(0.074)$ & $(0.086)$ \\
\hline \multirow[t]{2}{*}{ 2.3. Housing } & 0.032 & -0.076 & -0.006 & 0.304 \\
\hline & $(0.201)$ & $(0.224)$ & $(0.222)$ & $(0.195)$ \\
\hline \multirow[t]{2}{*}{ 2.4. Education } & 0.037 & 0.004 & 0.003 & 0.018 \\
\hline & $(0.034)$ & $(0.046)$ & $(0.040)$ & $(0.046)$ \\
\hline \multirow[t]{2}{*}{ 2.5. Health } & 0.018 & 0.012 & -0.019 & 0.047 \\
\hline & $(0.067)$ & $(0.069)$ & $(0.062)$ & $(0.065)$ \\
\hline \multirow[t]{2}{*}{ 3. Debt Service } & -0.104 & -0.121 & -0.102 & -0.123 \\
\hline & $(0.037)$ & $(0.046)$ & $(0.043)$ & (0.054) \\
\hline
\end{tabular}

This is a GMM estimation of equation 13. Standard errors in parenthesis.

Estimate is significant at $5 \%$ level if in bold characters, at $10 \%$ if in bold and italics.

Each row corresponds to a different regression, where the dependent variable is

the share of total expenditure represented by a given category.

Each column corresponds to a different set of controls, as detailed in table 2 
Table 6. Effect of fiscal performance on vote shares

\begin{tabular}{|c|c|c|c|}
\hline \multirow{2}{*}{$\begin{array}{c}\text { Dependent Variable: } \\
\text { Votes to party P } \\
\text { Regressor }\end{array}$} & \multicolumn{2}{|c|}{$\begin{array}{l}\text { Expenditure variables in per } \\
\text { capita terms }\end{array}$} & \multirow{2}{*}{$\begin{array}{c}\begin{array}{c}\text { Investment as } \\
\text { share of total }\end{array} \\
3\end{array}$} \\
\hline & 1 & 2 & \\
\hline Constant & $\begin{array}{l}29.663 \\
(2.224)\end{array}$ & - & $\begin{array}{l}\mathbf{2 9 . 2 3 2} \\
(1.978)\end{array}$ \\
\hline Votes to $\mathrm{P}$ in past election & $\begin{array}{c}0.498 \\
(0.027)\end{array}$ & $\begin{array}{c}\mathbf{0 . 3 8 9} \\
(0.026)\end{array}$ & $\begin{array}{c}0.524 \\
(0.026)\end{array}$ \\
\hline Deficit & $\begin{array}{l}0.026 \\
(0.019)\end{array}$ & $\begin{array}{c}0.025 \\
(0.018)\end{array}$ & $\begin{array}{c}0.024 \\
(0.015)\end{array}$ \\
\hline Deficit * incumbent & $\begin{array}{l}-0.049 \\
(0.023)\end{array}$ & $\begin{array}{l}-0.047 \\
(0.022)\end{array}$ & $\begin{array}{l}-0.040 \\
(0.019)\end{array}$ \\
\hline Investment Expenditure & $\begin{array}{l}-3.224 \\
(1.494)\end{array}$ & $\begin{array}{l}-0.493 \\
(1.134)\end{array}$ & $\begin{array}{l}-4.281 \\
(2.455)\end{array}$ \\
\hline $\begin{array}{l}\text { Investment Expenditure } \\
\text { *incumbent }\end{array}$ & $\begin{array}{c}\mathbf{5 . 9 0 4} \\
(1.719)\end{array}$ & $\begin{array}{c}3.290 \\
(1.439)\end{array}$ & $\begin{array}{c}9.887 \\
(2.970)\end{array}$ \\
\hline Current Expenditure & $\begin{array}{l}-1.571 \\
(1.784)\end{array}$ & $\begin{array}{c}0.119 \\
(1.380)\end{array}$ & - \\
\hline $\begin{array}{l}\text { Current Expenditure } \\
\text { *incumbent }^{\text {incula }}\end{array}$ & $\begin{array}{c}2.163 \\
(1.732)\end{array}$ & $\begin{array}{l}-1.730 \\
(1.339)\end{array}$ & - \\
\hline GDP Growth & $\begin{array}{l}133.971 \\
(30.768)\end{array}$ & $\begin{array}{l}74.783 \\
(24.054)\end{array}$ & $\begin{array}{l}121.765 \\
(30.898)\end{array}$ \\
\hline GDP growth*incumbent & $\begin{array}{l}-77.723 \\
(36.029)\end{array}$ & $\begin{array}{c}10.960 \\
(28.116)\end{array}$ & $\begin{array}{l}-61.450 \\
(36.249)\end{array}$ \\
\hline Observations & 2032 & 2032 & 2032 \\
\hline R-square & 0.234 & 0.196 & 0.232 \\
\hline
\end{tabular}

Notes: this table presents the results of estimating equation 17

Bold characters denote significance at $5 \%$. Bold and italics denote significance at $10 \%$.

Robust standard errors in parentheses

Columns 1 and 3 report Pooled OLS results, Column 2 reports OLS results with state/party effects

Incumbent is 1 if party $\mathrm{P}$ is in power at the time of the election, 0 otherwise 